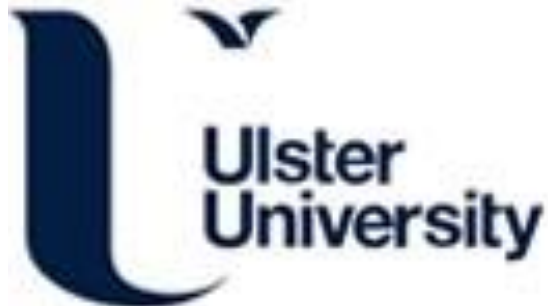

\section{Human Resource Business Partner Lifecycle Model: Exploring how the relationship between HRBPs and their line manager partners evolves}

McCracken, M., O'Kane, P., Brown, T., \& McCrory, M. (2017). Human Resource Business Partner Lifecycle Model: Exploring how the relationship between HRBPs and their line manager partners evolves. Human Resource Management Journal, 27(1), 58-74. https://doi.org/10.1111/1748-8583.12125

Link to publication record in Ulster University Research Portal

Published in:

Human Resource Management Journal

Publication Status:

Published (in print/issue): 16/02/2017

DOI:

10.1111/1748-8583.12125

\section{Document Version}

Author Accepted version

\section{General rights}

Copyright for the publications made accessible via Ulster University's Research Portal is retained by the author(s) and / or other copyright owners and it is a condition of accessing these publications that users recognise and abide by the legal requirements associated with these rights.

\section{Take down policy}

The Research Portal is Ulster University's institutional repository that provides access to Ulster's research outputs. Every effort has been made to ensure that content in the Research Portal does not infringe any person's rights, or applicable UK laws. If you discover content in the Research Portal that you believe breaches copyright or violates any law, please contact pure-support@ulster.ac.uk. 


\title{
Human Resource Business Partner Lifecycle Model: Exploring how the relationship between HRBPs and their line manager partners evolves
}

\begin{abstract}
The Human Resources Business Partner (HRBP) role is advocated as a way for Human Resource (HR) professionals and the HR profession to become more strategic and less transactional, necessitating the development of different competencies. Few researchers have examined how the HRBP Model plays out in practice, over time, from the perspective of HR professionals and their Line Manager Partners (LMPS). We collected data through interviews and focus groups with both these stakeholders at three UK organisations to understand the dynamics of the individual HRBP-LMP relationship. After analysing the data, we propose an HRBP Lifecycle Model. The Model suggests the relationship between the parties is dynamic, complex and dependent upon the organisational culture as well as the skills and competencies of the main stakeholders in the partnership.
\end{abstract}

Keywords: human resources business partner, line manager, competencies, Strategic HRM 


\section{INTRODUCTION}

The role of the Human Resource (HR) professional has changed significantly from the days of personnel departments, where the focus was on transactional tasks (Guest, 1991; Lawler, 2011), to the prevailing wisdom of today which suggests HR professionals must partner with line managers by aligning their work with the organisation's strategic direction (Dany et al., 2008; Jackson et al., 2014). The first movement toward this partnership approach was the HR generalist role, where the practitioner was "the first point of contact for employees while also liaising with business managers regarding HR matters" (Pritchard, 2010: 179). More recently, we have seen movement to the Human Resource Business Partnership (HRBP) role (Ulrich, 1998). The essence of the HRBP approach is that an HR professional can become a strategic partner with line managers to facilitate the attainment of business goals (CIPD, 2014; Ulrich, 1998). The influence of the HRBP approach is widespread, with some authors claiming it is "centre stage ... with significantly less attention paid to other [HR] roles" (Pritchard and Fear, 2015: 1). Thus, we wanted to understand how the HRBP role plays out in practice, over time, through the voices of those involved in the relationship, namely the HRBPs and their Line Manager Partners (LMPs). In doing so, we sought to explore key skills and competencies, their relationships and the cultural influences at various points throughout our proposed HRBP Lifecycle.

The lifecycle concept has often been used to examine organisational transitions. For example, the stages organisations go through over the course of their life (Lester et al., 2003; Quinn and Cameron, 1983; Smith et al., 1985) and product (or service) lifecycles from initial development to ultimate decline (Thietart and Vivas, 1984). In the present study, we use data from three organisations whose HR functions are at various stages of sophistication to illustrate the evolution of the relationships between the key stakeholders as they attempt to enact HR Business Partnering. In so doing, we highlight various issues and tensions, which 
emerged at what we saw as the critical stages of HRBP development. By understanding the relationship and cultural shifts, which occur as this approach unfolds, we suggest the key stakeholders will be better able to successfully manage this change. Such transitions have been noted in lifecycle theories as "crises". For example in Quinn and Cameron's (1983) much cited organisation lifecycle theory, it is proposed that after an initial period of creative expansion a "leadership crisis" may occur where tough decisions have to be taken regarding the future direction of the immature organisation. A key aim of this paper is to illustrate that, similar to the organisational lifecycle model, as HR business partnering is adapted and evolves a myriad of difficulties and tensions, as well as opportunities for the participants, can arise.

While Ulrich's (2012) HRBP model does not explicitly reference obstacles to developing HR competencies, other studies have done so. Factors such as encouraging LMP buy-in to the HRBP approach and upskilling HR professionals to become more "business savvy" are noted as problematic (CIPD, 2014; McCracken \& Heaton, 2012). Similarly, authors have identified the importance of balancing both transactional and strategic HR duties (Beer, 1997; Caldwell, 2003; Lawler, 2011) as well as tensions associated with the HRBP's dual role as both partner to management and employee advocate (Francis and Keegan, 2006; Kochan, 2004; Pritchard and Fear, 2015). In many ways, such tensions are intrinsically related to the organisational context or cultural circumstances faced by the main stakeholders. Thus, we also suggest that organisations need to consider what role culture plays when considering the operation of the HRBP approach.

With this in mind, we utilise the work of Goffee and Jones (1998) and Garrow and Martin (2012), whose perspective on culture can help us to understand key issues at the heart of the HRBP approach. Organisational culture has received significant attention and many authors have attempted to categorise its key 'ingredients' (see for example, Martin, 2002; 
Schein, 1985; Deal and Kennedy, 2000; Handy, 1993). Given the importance of partnership and relationship building between HR professionals and line/functional managers Goffee and Jones' (1998) Double S Cube model provides a useful lens from which to understand the HRBP process, because of its emphasis on how task and social relationships between stakeholders, in this case HRBPs and LMPs, can affect an organisation's culture. This paper contributes to the literature by examining in-depth, qualitative data from three organisations (one with a longitudinal dimension) where the HRBPs and their LMPs are at different stages of their individual relationships or lifecycle.

\section{HRBP transition: considering competencies}

Ulrich et al.'s (2012, 2013) model of HR professional competency domains is a comprehensive theoretical framework and, therefore, grounds this study. This model presents six key HR professional competency domains, which evolved from the analysis of over 20,000 survey responses and employed a multi-stakeholder approach. These domains are: (1) strategic positioner, which focuses on understanding the business context, the implications of that context and the creation of business goals; (2) credible activist, which includes the individual's interpersonal skills and results-oriented behaviour that builds trusting relationships; (3) change champion, where they demonstrate the ability to drive change, overcome resistance and build commitment; (4) capability builder, which involves strategically aligning HR to business drivers and creating a meaningful work climate; (5) being a HR innovator and integrator, with the aim of impacting business results; and (6) technology proponent, where they display knowledge and skills in relation to social networking, communicating and HR analytics.

While Ulrich et al. (2012) emphasise both the HR role and competencies needed, HRBP transition is also inextricably linked to the issue of devolution of HR responsibilities to the line. Thus, LMPs are a critical stakeholder in the process and organisations need to 
understand their readiness to embrace the change to HR Business Partnering (McCracken and Heaton, 2012; Brandl et al., 2009; Ulrich, 1998). There are three reasons to support the devolution of HR tasks to LMPs: (1) HRBPs can increase their strategic focus if LMPs assume more HR tasks; (2) line accountability can mean faster and more appropriate responses to HR issues, and (3) effective management of HR issues by LMPs can facilitate employee commitment (Brandl et al., 2009). These explain why devolution needs to be embedded in the HRBP approach. In fact, the role of LMPs in HR has become so important that some have even called for the movement of LMPs into full-time HR roles (Charan, 2014). Unfortunately, a theme in the literature is that line managers often lack motivation or competence to assume HR tasks (Dany et al., 2008; Keegan and Francis, 2010). One potential explanation for this is that they see HR tasks as less important relative to other priorities (Brandl et al., 2009). Additionally, drawing on change management literature, (see for example Vakola, 2014) a key requirement to create line manager buy-in to the HRBP model is the ability to illustrate the positive consequences, which may accrue. However, this can be difficult given that many senior and line managers still perceive the primary role of HR professionals as legal and moral guardians, to "keep the organisation out of trouble", as opposed to a function which contributes to organisational performance (Prichard and Fear, 2015; Jackson et al., 2014). This requirement for HRBPs to take a more business-oriented view could potentially compromise their ethical and employee advocate role (Winstanley and Woodall, 2000; Wright, 2008).

These differing perspectives concerning ownership of HR responsibilities may result in role ambiguity and tensions when it comes to building robust and effective relationships between HRBPs and LMPs (Keegan and Francis, 2010). As such, building the relationship between the LMP and the HRBP, in order for the HRBP to become the "trusted adviser", is critical and, thus, explored in this study. In effect, the ultimate aim of the transition towards 
the HRBP approach is to allow LMPs to move from being dependent on HR, where "HR is doing everything", to being "self-sufficient", and managing key HR tasks (Keegan and Francis, 2010: 890).

The review of the literature reveals tensions and potential conflicts surrounding the role of HRBPs, the HR duties that should be performed by LMPs, and what constitutes effective HRBP-LMP relationships (Caldwell, 2003). While the HRBP literature frequently discusses the alignment of HR to organisational strategy, the dynamic nature of the situation and the evolving relationships that ground HRBP are rarely fully explored. This is supported by Jackson et al. (2014: 12) who suggest "HRM systems co-evolve along with business strategies". Clearly then, an organisation's culture influences the role HR plays and ultimately how effective HR professionals and LMPs can be in transitioning to and enacting the HRBP arrangement.

\section{HRBP transition: culture and relationships}

To further emphasise the potentially turbulent nature of any transition to the HRBP approach with its objective of facilitating a more strategically focused HR provision, Pritchard (2010) suggests it is often coupled with changes in HR structure such as the creation of shared service models or small, centralised units of functional experts. Given these factors, there is a need to explore how an organisation's culture influences the transition from a more transactional modus operandi to a strategic HRBP approach.

Garrow and Martin (2012) reference Schein's (1985: 9) well established definition of organisational culture as "a pattern of basic assumptions - invented, discovered or developed by a given group as it learns to cope with its problems of external adoption and internal integration". Hence, HRBPs and LMPs need to learn a "new" pattern of basic assumptions relative to the redistribution of HR roles and responsibilities, if the partnership is to work. Garrow and Martin (2012) further point out that culture plays a significant role in change 
programmes but that views regarding the manageability of culture change differ (Meek, 1988). Clearly, the HRBP transition represents major change requiring "a few change agents who disrupt the underpinning behavioural patterns so that new behaviours are introduced and role-modelled" (Garrow and Martin, 2012: 101). The topic of culture is broad, with an extensive literature (e.g. Martin, 2002; Schein, 1985). Rather than discussing the multitude of cultural models, we focus on, and use, Goffee and Jones's "Double S Cube" (1998), because of its emphasis on how relationships between stakeholders can affect an organisation's culture. In summary, their model is a $2 \times 2$ matrix using the constructs of sociability and solidarity. Sociability refers to how partners in the relationship get along in terms of friendliness and mutual respect and ultimately represents the more emotional side of culture. Solidarity, the task side of culture, relates to the need to create a shared understanding of tasks/goals. Given relationship building is an essential element in ensuring a successful transition to a HRBP approach, this model offered a useful theoretical lens to analyse the transition. In essence, relationship building is all about solidarity and sociability and the preceding literature review has exposed challenges related to both these dimensions.

The "Double S Cube" model contains four culture types. The first, communal culture, is high on both the sociability and solidarity dimensions, meaning that parties get along well and have a high degree of agreement on tasks and goals. The second, networked culture, is high on sociability but low on solidarity, thus, while relationships are positive, there lacks goal and task agreement. The third, mercenary culture, is low on sociability and high on solidarity, meaning that while there is high task and goal agreement, relationships are "unfriendly". Finally, the fourth, fragmented culture, is low on both sociability and solidarity, and thereby, lacks both friendliness and task/goal agreement. We believe that our analysis across the three organisations in this study could help determine which of the four culture types may best support progression towards effective HRBP-LMP relationships. 
In conclusion, our review of the literature suggests that limited research has examined the HRBP role and transition from the perspective of HR professionals and their associated LMPs. Exceptions include the ethnographic study of HR professionals within a single organisation by Pritchard (2010) and the in-depth study of HR professionals by Keegan and Francis (2010). In neither study was the perspective of LMPs examined. Given this backdrop, we examined a broad research question: How does the HRBP-LMP relationship evolve over time? More specifically, we explored the following dynamics: how the HRBP role, skills and competencies develop; how the relationship between the HRBP and their LMP changes over time; and what influences the relationship between the HRBPs and LMPs. In examining these questions, we proposed that both the competencies of each stakeholder and the cultural context that characterises the relationship between them would influence the success of the HRBP approach.

\section{METHODOLOGY}

We employed an interpretative approach, conducting case studies in three large UK organisations, which we named Insurance Co, Transit Inc, and Energy Ltd. In total, we interviewed 55 stakeholders from various functions and levels. In the case of Energy Ltd, we benefited from longitudinal data as we conducted interviews twice, spanning a five-year period (see Table 1). More specifically, we spoke with 21 LMPs and their HRBPs (from Transit Inc and Energy Ltd), as well as three additional line managers who were not officially partnered with a HRBP (Insurance Co). Interviews lasted between 60 and 75 minutes, were semi-structured and asked participants to discuss the role of HR in corporate strategy, the roles and responsibilities of both HRBPs and LMPs, how these had changed, the quality of their relationships, and any challenges related to their skills or competencies.

In round two of the data collection in Energy Ltd, we conducted one 60-minute focus group with seven employees who had no line responsibility. Their demography was 
representative of the organisation in which they worked, including employees with trade, administration, and professional backgrounds. The focus group was less structured and relatively open in nature, but we did have a series of key issues that we sought to explore related to HR roles and responsibilities. Access issues prevented focus groups in the other two organisations. The focus group and interviews were audio-recorded and transcribed.

Insert Table 1 about here

We used Yin's (2009) case study approach which involves utilising a theoretical underpinning to empirically examine a phenomenon in a real-life setting. In our case Ulrich's (1998) and Ulrich et al.'s (2012) HRPB model (and associated HR competency domains) as well as Goffee and Jones's Double S Cube culture model (1998) provided our theoretical lenses. We then applied these concepts across the various HRBP-LMP relationships within the three organisations to identify different representations of the HRBP-LMP relationship. We employed an interpretative approach to our data collection and analysis, which "assume[s] that people create and associate their own subjective and intersubjective meanings as they interact with the world around them. Interpretive researchers thus attempt to understand phenomena through accessing the meanings participants assign to them" (Orlikowski and Baroudi, 1991: 5). Therefore, we listened carefully to the experiences of the participants to ascertain their perspective of the HRBP-LMP dynamics to assist us in creating meaning about the range of different relationships present across the three organisations.

For the analysis, we followed Strauss and Corbin's (1990) interpretation of grounded theory allowing the emergence of important themes and patterns in the data while assuming some prior knowledge. Therefore, each author separately conducted open coding of the data manually from one of the case study organisations to identify key themes emerging from their case. Subsequently, as a team, we conducted axil coding enabling themes to be refined, discussed, debated, and reduced. During this stage, we identified different stages and 
challenges in the HRBP-LMP relationship. Finally, in the selective coding stage, all researchers agreed on the stages of the proposed HRBP Lifecycle. Table 2 gives a brief overview of the three organisations, while Table 3 presents a summary of how the coding framework developed.

\section{Insert Tables 2 and 3 about here}

\section{FINDINGS}

We present our findings relative to the three stages of our "HRBP Lifecycle Model", developed from our analysis of the data: (1) Exploration, (2) Developing an Effective Partnership and (3) Maintaining, Excelling and Maladaptation (see Figure 1 and Table 4).

Insert Figure 1 and Table 4 here

\section{Stage One: Exploration}

The critical first stage of the lifecycle requires organisations to assess their "readiness" for an HRBP approach. As we interpreted the data, we saw our participants discussing the need for a catalyst to help initiate this change. One example was provided by the HR Director in Energy Ltd:

\footnotetext{
The catalyst for change was what was happening in the market ... when we looked at the benchmarks we were not even in the top twenty in terms of the most efficient utility ... [We] went down that [efficiency] route with the HR function and other functions in terms of the specialists who became more multi-skilled and more generalist.
}

Without this catalyst, we think Energy Ltd would not have begun the exploration phase. Yet, we also saw the HR Director as a catalyst. Without his championing of the HRBP approach, 
it would have been difficult to establish. A Senior Manager in Transit Inc also described how the catalyst for change was related to movement in the organisational strategic direction:

[The rationale for using HRBP] was very much in line with ... the strategic aims of the business, it was very much what HR support will you require to deliver these things, and that would be part of [name of HRBP's] role. But if [he] is living and breathing the shortterm objectives and the longer-term objectives, then he can be picking up the HR issues and working very much hand in hand [with LMPs].

Not only was the change in strategic direction and leadership a catalyst, we also saw the importance of creating the right climate for the HRBP approach as illustrated by an HRBP from Transit Inc:

I think the first thing you have to do before even deciding if you want to go down that route [HRBPs], is to have a very, very clear HR strategy. The worst thing in the world is you get somebody in as a business partner and they spend their whole life doing disciplinarys and grievances, you know. Why bother, that is not a business partner?

In contrast to the strategic catalyst seen in these two organisations, Insurance Co was at an earlier stage of considering the strategic contribution their HR professionals could make. One Senior LMP illustrated this when he suggested that HR were "starting to become participants in strategy conversations".

In each of the three organisations, the catalyst, or potential catalyst, was interlinked with the HR professional becoming involved at the strategic level. We, therefore, saw a clear need for the potential HRBP to develop strategic competencies, consistent with Ulrich et al.'s (2012) strategic positioner competency domain. In these organisations, adding a strategic 
dimension to the HR professional role necessitated a cultural change in the relationship between the HRBPs and the LMPs. We see this task as being a responsibility of the HR professional. Therefore Ulrich et al.'s (2012) change champion competency domain was important if the potential HRBP was to successfully create buy-in among organisational stakeholders. For example, the HR Director in Transit Inc described the movement toward the HRBP approach as a "journey ... you are talking about a culture that has been here for a long time ... you can't just flick a switch overnight, this is all about engagement in hearts and minds, so it's a gradual thing”. This also suggested to us that those tasked with creating an effective HRBP model needed to understand and develop strategies to move the organisational culture away from what we feel represents Goffee and Jones's (1998) fragmented culture. When they were at this point, Energy Ltd and Transit Inc participants discussed what we saw as low levels of sociability and solidarity, which resulted in relationship challenges related to resistance to the HRBP approach and a lack of understanding and buy-in from line managers to the importance of the HR task.

This lack of readiness for cultural change was evident in Insurance Co, where senior HR personnel suggested that the organisation was not yet ready to embrace the strategic HRBP role. The Senior Manager responsible for administration, including HR, noted that HR was still widely viewed as a "delivery centre" focused upon legislative compliance. Several Insurance Co participants raised concerns about potential inconsistencies in HR policy and practice that could hamper the implementation of the HRBP approach. In the words of the HR Director: "we have talked about that [formal HRBP], I'm not overly comfortable with it...there can be a degree of inconsistency". To us, quotes such as these also reveal the tensions present in this stage as parties try to negotiate the HR transition from "policy guardians" towards business partners. Therefore, there was also a need for HR to develop 
more capability building as well as change champion competence in order to build commitment, address the tensions present, and negotiate resistance to change.

While we did see evidence in Insurance Co that HR professionals wanted to move towards an HRBP approach, one HR Advisor bemoaned, "sometimes [I] wished that some of our managers had a little bit more courage to make decisions". She went on to suggest that considerable efforts were made to "empower them with education and information sessions" and concluded that HR professionals must be strong and supportive: "arming them [line managers] with all the information that they need, and guidance, you know, being available, if a manager comes and says can I meet with you as a sounding board?" Indicative of being in Stage One of our model, the apparent lack of a change catalyst presented challenges for Insurance Co in creating buy-in towards an HRBP approach.

\section{Stage Two: Developing an effective partnership}

Transition to Stage Two of the lifecycle, in the case of both Transit Inc and Energy Ltd, occurred where an appropriate catalyst was present, an agreement was reached to change how HR operates, the contextual circumstances aligned, and appropriate skillsets were in place.

We believed that this stage can be best characterised through Goffee and Jones's (1998) networked culture, where key players in the HRBP approach begin to foster closer working relationships depicted by higher sociability, but lower solidarity given that the parties have not fully established a shared understanding of roles and responsibilities. The importance of relationship building was clearly evident in our data, as well as challenges associated with the changes to HR's roles, responsibilities and protocols. Thus, we suggest that HR professionals need to develop their credible activist competency (Ulrich et al., 2012). Many participants acknowledged the importance of competencies related to building trust and mutual understanding in the HRBP-LMP relationship. The need for role-fit was highlighted by the HR Director from Energy Ltd. He explained that before becoming an HRBP, the Energy Ltd 
HR professional needed to consistently demonstrate behaviours fundamental to the HR Business Partnering role. For example, the need to be "practical yet provocative" when working with LMPs, a behaviour he found in short supply:

I would love another [Senior HRBP] person ... we have tried agencies, we've brought in senior people, experienced people and it just hasn't worked. ... I don't want somebody coming in here that takes the whole HR team back in time to an old way of doing things...

To us, one of the most fundamental elements in developing an effective partnership is the choice of HRBP-LMP pairs. As one Energy Ltd LMP suggested: "You need to get the right HRM people involved - I have worked with a good one and a bad one and it is important that you can work with the person".

Again, these comments represented to us challenges concerning the cultural element of solidarity (Goffee and Jones, 1998). Interviewees also highlighted that once the relationship is established, there is a need for clear and agreed responsibilities to minimise role ambiguity, as one LMP from Energy Ltd elaborated: "For the model to work, we need to think about 'where the lines cross' - where does the ownership for things come from - where does it start and stop". Similarly, an LMP from Transit Inc stressed the importance of HRBPs fully understanding "what was being expected of them ... [enabling them] to build up that working relationship". To support this, we found many pairs had formulated individual partnership protocols to enable seamless working. One Senior Manager from Energy Ltd reflected his own experience in saying there are "no problems in contacting HR $-24 / 7$ - everyone is comfortable with that".

In addition to clarifying roles and relationships, the HRBP must continue to be seen as a credible activist (Ulrich et al., 2012). In the interviews, we frequently heard terms such as 
building visibility, credibility and trust. We saw evidence of Goffee and Jones's (1998) culture element of sociability in these comments. For example, a relatively new HRBP in Energy Ltd related how she had quickly learned that her toolkit now included "a pair of boots and a hardhat", which enabled her to visit her LMPs' worksites, enhance her visibility, and build relationships. Clearly indicative of the solidarity theme, we noted that several LMPs from Energy Ltd and Transit Inc asserted that HRBPs were key team members, or "another hand on deck when needed" (HR Advisor, Energy Ltd). However, an LMP from Transit Inc stressed that the essential element at this stage was continuing to reinforce credibility "I've seen HR managers previously, they didn't establish credibility ... they have to be strong, they have to be firm, they have to come with the right approach".

At this relationship building stage, we saw evidence that establishing trust required the HRBP to develop an understanding of the business. As one Energy Ltd LMP suggested:

[HRBPs] need to ... spend time getting out there and understanding the business, build a wee bit of trust, make sure people can see ... that you're coming from the right place ... not to act like a gatekeeper ... it's to actually help them with the business.

Linked to visibility, credibility and trust, we saw the need for HRBPs to display business savvy and an appreciation of the organisational strategic direction. For example, an HRBP from Transit Inc described how her expertise was utilised in a more nuanced way by LMPs: “[previously] you didn't need those relationships ... it was just, I'll give you this advice, this is what you do ... now you have to understand their business and the pressures they are up against". To us this quote illustrates that Ulrich et al.'s (2012) capability builder competency, with a focus on HR strategic alignment, is important at this lifecycle stage. In particular, we saw that this stage was characterised by HRBPs and LMPs paying particular attention to "aligning strategy, culture, HR practices and behaviour" (Ulrich et al., 2012: 
121). We further saw evidence of this in Energy Ltd, where the parties were focussing on questions concerning business trends, drivers, and HR priorities.

For the HRBP approach to work, it was evident to us that the other key stakeholder in the partnership, the LMP, also needed to establish credibility and develop their ability to handle HR issues. Several managers argued that HR professionals needed to encourage LMPs to become more independent in HR matters. A Senior Manager at Energy Ltd suggested that the HRBP approach resulted in “... line managers [who] are very much empowered to get on with a lot of the stuff themselves .... we need them to know themselves without constantly having to refer back to HR". In Transit Inc, we saw evidence that LMPs had a burgeoning set of people management skills, which again illustrated to us that a progressive HRBP approach was in operation, with clarity regarding responsibilities and roles. For example, the HR Director reflected that:

the day-to-day grievances and kinds of harassment or bullying ... we expect the manager to deal with those ... it has been a bit of an educational process for the managers, in the past these have been dealt with by HR, or constrained by HR who have perhaps wanted everything to go through them.

Although the majority of HRBPs in Energy Ltd were relatively pragmatic about LMPs' assumption of HR responsibilities some tensions also arose at this development stage. For example, one HRBP found that "where you have a manager who won't accept his role - it's frustrating". Thus it was clear to us that the development stage was not without tensions among the key relationship stakeholders.

Ultimately, the partnership development stage underpins the whole concept of HRBP, and for some organisations there may be a temptation to feel that the transition is complete 
when this stage has been enacted. However, as is shown below, our analysis revealed other dynamics which need to be considered as the HRBP approach matures.

\section{Stage Three: maintaining, excelling, and/or maladaptation}

The first two stages of the lifecycle represent the traditional embedding of the HRBP approach within an organisation. Through our interviews and focus groups, we uncovered different ways in which individual partnerships evolved over time. These remain dynamic and present differing challenges to the actors involved. In stage three we saw that three main challenges that could emerge for the dyads. We do not see these as mutually exclusive, or fully incompatible, and suggest that the dyads could move between these three challenges dependent on individual competencies, organisational culture, and the inherent relationship between the partners. Therefore, given the complexity of the issues at hand, we stress that stage three is not simply a choice of three different outcomes.

Challenge 1: maintaining. One challenge faced by our participants was maintaining an effective relationship over the longer term. Our interpretation of the data suggested that many of the dyads in Transit Inc, who had more recently adopted the HRBP approach, were working hard to maintain the day-to-day operation of the partnership. We also saw evidence of this challenge within some of the dyads in Energy Ltd. In maintaining their partnership, we saw evidence of these HRBPs and LMPs displaying elements of Goffee and Jones's (1998) communal culture. Specifically, we saw both sociability, where the relationships were considered friendly, and solidarity, where there was clear evidence of high task agreement. One HRBP from Transit Inc illustrated the high level of collegiality between herself and her LMPs:

it's a really nice organisation, and people are very helpful, so if they phone you and you happen to be on a day off, they will be really apologetic; whereas, I've worked in places 
and it doesn't really matter, and they don't even ask are you in work or are you not, it's just like you need to take my call.

As evidence of solidarity, our review of the data revealed that shared ownership of the business priorities underpinning the partnership was embedded in their roles. Both HRBPs and LMPs discussed the need to have a stake in key business issues. As one LMP in Transit Inc summarised: "[HRBPs] are part owners of the problems ... [they] are actually sitting down in their business meetings, picking up where the problems are, trying to resolve them, whereas ... [in the past] ...the business tried to do things on their own”. A similar example emerged from the Energy Ltd employee focus group. Participants discussed the advantage of HRBPs being their dedicated point of contact, as opposed to having no clear owner: "we had problems when there was three different $[\mathrm{HR}]$ people dealing with the one issue, and it was all over the place ... but when you get the one person it stabilises, it goes forward". Such examples also highlight to us the importance of the capability builder competency in this challenge (Ulrich et al., 2012).

In Transit Inc, we saw that the interrelatedness of credibility, trust, visibility and augmented skill sets culminated in many of their HRBPs now being seen as core team. In the words of one senior manager, HRBPs were not "treat[ed] any differently than ... the rest of my team" and were "involved in all of the team meetings, she is involved in all the communications and any decisions we make as a team". This quote clearly showed to us that cultural sociability and solidarity (Goffee and Jones, 1998) underpin the challenge of maintaining the partnership.

Challenge 2: excelling. The second challenge, evident within some of our dyads, related to both HRBPs and LMPs excelling in their roles. We saw that as HRBPs excelled they began moving towards a more strategic role, with an increased focus on futureorientation. We saw evidence of this among several long-serving HRBPs in Energy Ltd, 
suggesting that this would most likely occur in a mature relationship. These HRBPs reiterated the importance of becoming more "proactive and intuitive", effectively "influencing" and "challenging" their LMPs on a wide range of business issues. The Energy Ltd HR Director summed up the excelling challenge for HRBPs when he suggested they "identify the problem before it arises". In essence, to us, he was describing HRBPs becoming more provocative where they are "able to ask the question in the right way, sometimes using humour or whatever, doing it with dignity, tact, respect for the individual, but being able to be open about things ... being a provocateur is about opening the challenge". From our perspective, to be a provocateur the relationship between the HRBP and LMP needs to have both solidarity and sociability elements. In our data, this was reflected in relationships based upon both respect and the ability to challenge. To enable this, the HRBP needs to display change champion competencies (Ulrich et al., 2012).

In Transit Inc too, we saw evidence of HR professionals excelling through a strategic, organisation-wide OD initiative, which according to the HR Director: "HR devised, created, and [were] the architect behind it, but the business lead it". To us, this also exemplified Ulrich et al.'s (2012) HR innovator and integrator competencies where HRBPs need to focus on a small number of important business issues. Within Energy Ltd, we saw an initiative to further enable both HRBPs and LMPs to excel and contribute at higher levels. This involved a very deliberate process of facilitating a select number of line managers taking on more HR responsibilities because the Senior HRBP "felt that they had a number of the attributes of a good HR person”. She went on to describe how a possible longer-term outcome from this initiative may involve these LMPs moving into permanent full time HR roles or furthering their careers into more senior line positions. For HRBPs, the freeing up of their time from HR responsibilities could then enable them to undertake more strategic business roles. 
Challenge 3: maladaptation. As HRBPs integrate into line departments, the potential for relationships based on over-reliance and dependence also emerged. This could, result in what we consider maladaptation, or as the HR Director in Energy Ltd described it, things getting "too cosy". In many ways, this finding resonated with the issues already addressed in Stage Two concerning the need to upskill LMPs' HR competencies and encourage them to fully embrace HR responsibilities. Moreover, this exemplified the potential reversion to what Goffee and Jones (1998) call a networked culture in that the relationship between the parties (e.g. sociability) is strong but solidarity appears low as the two parties may no longer share a common vision on roles and responsibilities. For example, a number of years into the HRBP approach, members of Energy Ltd noted that some LMPs needed to be reminded of their HR responsibilities to counter the tendency for them to expect their "hands [to be] held". One Energy Ltd HRBP described how they "gradually crept in ... now people rely so heavily on you ... I was off for a week and I came back in and the lady who looks after [LMP] ... says, [LMP]'s been lost without you this week...”.

Some LMPs from Energy Ltd admitted that they had already become overly reliant upon their HRBP, with one reflecting how he was "in touch a lot of the time, in fact she might complain that I plagued her to be honest”. Relatedly, HRBPs within Energy Ltd and Transit Inc conceded that occasionally there was the temptation to revert to administrative tasks, neglecting the strategic aspects of the job: "now I get involved in everything from going out to home visits with the guys, right through to doing letters". In a similar vein, an HRBP in Transit Inc also admitted that it was simply easier to perform certain HR duties that should have performed by her LMP. As we reflected upon such comments, it became clear that within a single HRBP-LMP relationship there could be multiple challenges. For example, one HRBP suggested that maladaptation occurred on "certain HR duties", but not all, suggesting that other elements of the relationship were at least being "maintained". Her 
comments also illustrated the downside of too much cultural sociability, or an overly friendly relationship between a HRBP and LMP. She reflected that "[My LMP was] one of the loveliest men I have ever worked with, ...., and it was like, so will you do this and will you do that, and you go awh yeah, yeah, yeah".

We also saw evidence of maladaptation and tension during the Energy Ltd focus group, where one employee stated that the HRBPs are "not personnel any more, they wouldn't be here as a representative of you, they would be here as a representative for management now". When reflecting upon these comments we saw the potential for a communal culture, with solid solidarity and sociability, between HRBP and LMP to lead to a scenario where general employees view their relationship as "too close". Ultimately if such a scenario continues, the organisation may not fully realise the benefit of the HRBP Model as tensions between HR, line managers and other employees may become heightened. Such examples suggest that the HRBPs can lose their focus on the Ulrich et al. (2012) strategic positioner and change champion competency domains.

Our analysis of the results enabled us to develop the HRBP Lifecycle Model. In the next section, we discuss this model in relation to the literature.

\section{DISCUSSION}

Few studies have examined the dynamics of the HRBP transition over time and included the perspectives of key stakeholders from multiple organisations. This paper addresses the gap by analysing three case organisations, in different stages of HRBP adoption. In so doing, we answer Jackson et al.'s (2014: 35) call to examine "the dynamics of effective strategic partnerships between HR professionals and managers". The research revealed that the HRBP transition can be complex as HRBPs and LMPs navigate new relationships, roles, and responsibilities. Moreover, it is not a predictable, linear process, as several different 
challenges can emerge depending on key stakeholder competencies and relationships, as well as organisational culture.

\section{HRBP lifecycle model development}

While our study confirmed much of the existing research concerning both the effectiveness and challenges of the HRBP approach, we add important contributions to the debate, particularly in relation to the longer-term dynamics of the approach. Specifically, we developed our HRBP Lifecycle Model (see Figure 1).

In Stage One, Exploration, we see the focus on assessing and promoting the readiness for the HRBP approach. Key themes emerged regarding: aligning the HRBP concept to strategic direction (including the need for a catalyst and encouraging readiness to change); preparing all parties for a significant culture change; providing a rationale for moving towards the HRBP approach, and creating LMP buy-in. At this stage, organisations need to move from what Goffee and Jones (1998) call a fragmented culture type where a lack of sociability (e.g. tensions in the relationship) and solidarity (e.g. lack of shared understanding of roles/tasks and goals) between HR and other parts of the organisation may be prevalent. Such factors need to be addressed if the HRBP approach is to be fully embraced. Also at this stage, HR professionals need to draw upon their strategic positioner and change champion competency domains (Ulrich et al., 2012) in order to create stakeholder buy-in. While reflective of current HRBP literature (e.g. McCracken and Heaton, 2012; CIPD, 2014; Ulrich, 1998), this highlights that not all organisations are ready for the HRBP approach.

For progression into Stage Two, Developing an Effective Partnership, the creation of a strong HRBP-LMP relationship is critical. In this stage, organisations need to encourage elements of Goffee and Jones's (1998) networked culture, provide support for the parties to get along (i.e., high sociability), and yet realise that there may still be some complexities before role clarity can be agreed upon (i.e., low solidarity). Our research suggests that the 
matching process is extremely important and that the competencies of key stakeholders need to be developed to sustain relationships. Hence, in this stage, credibility and augmented business acumen is required for HRBPs to be taken seriously (Charan, 2014; Pritchard and Fear, 2015), consistent with Ulrich's credible activist competency domain. Concurrently, LMPs need to develop their HR expertise. Without this dual credibility and expertise building, it will be difficult for an effective partnership to develop. During this process, HRBPs need to become more business savvy, whilst the LMPs need to develop their people skills (Dany et al., 2008; Keegan and Francis, 2010).

When an effective partnership is established, our empirical data illustrated that the HRBP-LMP relationship still faces challenges. This is reflected in the third stage of our lifecycle where individual relationships may encounter challenges broadly associated with what we have called maintaining, excelling, and maladaptation. In maintaining, parties have moved beyond developing the partnership and their new responsibilities and now seek to maintain the relationship. As such, both parties understand their relationship and their roles, and have established effective protocols, but, for some, this may not provide intrinsic satisfaction indefinitely; indeed we believe simply maintaining the relationship will not in itself enable HRBPs to become more strategic and further their careers and the profession. Rather, we see the next concept of excelling as a potential opportunity for either party to develop their role, and gain more responsibility.

We see excelling as positive transition for HRBPs. They have become embedded in their organisation, are now strategic players and are challenged to become even more strategic and proactive. As such, those HRBPs who are in this excelling category demonstrate abilities related to being proactive, intuitive and challenging their LMPs in a constructive, provocative manner. In essence, they become the quintessential trusted advisor reinforcing Wright's (2008) finding that HRBPs and their LMPs need a positive and proactive 
relationship. Thus, this challenge reflects Goffee and Jones's (1998) communal culture, as the parties continue to be high on both the dimensions of sociability, or friendliness, and solidarity, or goal agreement. We also see an increased focus on the HR innovator and integrator competency domains (Ulrich et al., 2012) as HRBPs concentrate on innovating and integrating HR practices to ensure they influence important business issues. LMPs, too, can benefit from the challenge of being in an excelling relationship. Specifically, LMPs gain skills that could enable them to move towards higher management or HR roles. The latter may assist with HR succession issues.

In many ways the third challenge, maladaptation, is the downside of the HRBP approach and can occur when the LMP becomes overly dependent upon their HRBP. This in turn can result in the HRBP having to revert to non-strategic, administrative tasks to continue to service the partnership. It can occur because of the breakdown of an HRBP-LMP relationship, or a lack of skills and competence in either partner. We propose that such a scenario could necessitate a reassessment of the partnership as the closeness in both physicality and accessibility makes the LMP over-reliant on their HRBP. Thus, while the relationship between the parties remains strong, they no longer see eye-to-eye on roles, and we see the potential re-emergence of a networked culture, high on sociability but low on solidarity combined with insufficient usage of the strategic positioner and change champion competency domains (Ulrich et al., 2012).

Although we identify three broad challenges, we suggest that the status quo of maintaining will continue indefinitely across all relationships. Thus, organisations need to be prepared for either, or both, of the partners moving towards excelling or maladaptation, therein signalling the need to redefine or reorganise the individual HRBP-LMP relationship. This could involve either of the partners moving into different roles, thereby creating the 
need to revisit stage two of the lifecycle and establish a new partnership with someone different.

\section{CONCLUSION, LIMITATIONS AND FUTURE RESEARCH}

This study is among the few to examine the HRBP approach in detail, from the perspective of HR professionals, LMPs, and employees, using qualitative data. Although scholarly work has discussed the HRBP model, little examines how this model plays out in practice and how it evolves over time. The limited research that does exist tends to view this as a linear model, largely ignoring the messiness, the cultural dynamics, and the potential for maladaptation. In contrast, our study highlights the role that culture and competencies play if this partnership is to truly develop and thrive.

We demonstrate how the implementation of the HRBP approach can enable HR professionals to gain broader business skill sets, allowing them to more effectively, and confidently, influence both strategic direction and the senior management team. In particular, we show that many of Ulrich et al.'s (2012) HR competency domains are developed, and become important, when successfully transitioning to the HRBP model. In addition, we saw evidence that the LMPs can gain skills from being involved in the HRBP approach giving them opportunity to take on other HR or business roles.

Our paper highlights the significance of the relationships between HRBPs and LMPs. Therefore, HR professionals need to acknowledge the importance of the relational aspect, mutual credibility and the ability to collaborate, challenge and engage with their line manager partner through a fluid and dynamic relationship. We believe that this study provides a springboard for future research into the HRBP role, particularly in relation to studying continuing partnership dynamics. Research would benefit from longitudinal and international studies. More specifically, the collection of data pre, during, and post-introduction of the HRBP approach would be a valuable contribution, potentially refining our lifecycle model. 
Additionally, there are limited investigations of non-HRBP models (Pritchard and Fear, 2015). Our results show that the "perfect" HRBP Model may not exist for all organisations and that the relationships are indeed dynamic. Future work could examine other HR models to determine the extent to which they better fit the cultures and needs of differing organisations.

Arguably, there is a selection bias in our study. While selection bias is less of an issue in qualitative research, the reality remains that all three organisations examined were interested in the HRBP approach and investigating innovative ways of utilising their HR departments. Future research should examine organisations where there is more active resistance to the HRBP approach to uncover whether any new insights can be gained for our proposed model. 


\section{REFERENCES}

Beer, M. (1997). 'The transformation of the human resource function: resolving the tension between a traditional administrative and a new strategic role'. Human Resource Management, 36: 1, 49-56.

Brandl, J., Madsen, M.T. and Madsen, H. (2009). 'The perceived importance of HRM duties to Danish line managers'. Human Resource Management Journal, 19: 2, 194-210.

Caldwell, R. (2003). 'The changing roles of personnel managers: old ambiguities, new uncertainties'. Journal of Management Studies, 40: 4, 983-1004.

Charan, R. (2014). 'It's time to split HRM'. Harvard Business Review, 92: 7, 33-34.

Chartered Institute of Personnel and Development. (2012). Business Savvy: Giving HR the Edge. Research report - phase 1. London: Chartered Institute of Personnel and Development.

Chartered Institute of Personnel and Development (CIPD). (2014). HRM Business Partnering. Retrieved January 06, 2015 from http://www.cipd.co.uk/hrresources/factsheets/hr-business-partnering.aspx.

Dany, F., Guiedri, Z. and Hatt, F. (2008). 'New insights into the link between HRM integration and organizational performance: the moderating role of influence distribution between HRM specialists and line managers'. The International Journal of Human Resource Management, 19: 11, 2095-2112.

Deal, T. E. \& Kennedy, A. A. (2000). The New Corporate Cultures: Revitalizing the workplace after downsizing, mergers and reengineering, London: TEXERE Publishing.

Francis, H. and Keegan, A. (2006). 'The changing face of HRM: in search of balance'. Human Resource Management Journal, 16: 3, 231-249.

Garrow, V. and Martin, G. (2012). 'Organisational culture and cultural integration', in H. Francis, L. Holbeche and M. Reddington (eds.), People and Organisational Development: A New Agenda for Organisational Effectiveness, London: Chartered Institute of Personnel and Development.

Goffee, R. and Jones, G. (1998). The Character of a Corporation: How Your Company's Culture Can Make or Break Your Business (1st ed.), New York: Harper Business.

Guest, D.E. (1991). 'Personnel management: the end of orthodoxy?' British Journal of Industrial Relations, 29: 2, 149-175.

Handy, C. (1993). Understanding Organizations, ( $4^{\text {th }}$ Ed) London: Penguin Books Ltd.

Jackson, S.E., Schuler, R.S. and Jiang, K. (2014). 'An aspirational framework for strategic human resource management'. The Academy of Management Annals, 8: 1, 1-56.

Keegan, A. and Francis, H. (2010). 'Practitioner talk: the changing textscape of HRM and emergence of HRM business partnership'. The International Journal of Human Resource Management, 21: 6, 873-898.

Kochan, T.A. (2004). 'Restoring trust in the human resource management profession'. Asia Pacific Journal of Human Resources, 42: 2, 132-146.

Lawler, E.E. (2011). 'Celebrating 50 Years: HRM: time for a reset?' Human Resource Management, 50: 2, 171-173. 
Lester, D.L., Parnell J.A. and Carraher S. (2003). 'Organization life cycle: a five-stage empirical scale'. The International Journal of Organizational Analysis 11: 4, 339354.

Martin, J. (2002). Organizational Culture: Mapping the Terrain, Thousand Oaks, CA: Sage Publications.

McCracken, M. and Heaton, N. (2012). "From "tucked away" to "joined at the hip": understanding evolving relationships within the HRBP model in a regional energy company'. Human Resource Management Journal, 22: 2, 182-198.

Meek, V.L. (1988). 'Organizational culture: origins and weaknesses'. Organization Studies, 9: $4,453-473$

Orlikowski, W.J. and Baroudi, J.J. (1991). 'Studying information technology in organizations: research approaches and assumptions'. Information Systems Research, 2: $1,1-28$.

Pritchard, K. (2010). 'Becoming an HR strategic partner: tales of transition'. Human Resource Management Journal, 20: 2, 175-188.

Pritchard, K. and Fear, W. (2015). 'Credibility lost: attempting to reclaim an expert identity in an HR professional context'. Human Resource Management Journal, 25: 3, 348363.

Quinn, R.E. and Cameron, K.S. (1983). 'Organizational life cycles and shifting criteria of effectiveness: some preliminary evidence'. Management Science, 29: 1, 33-51.

Schein, E.H. (1985). 'Defining organizational culture'. Classics of Organization Theory, 3: 490-502.

Smith, K.G., Mitchell, T.R. and Summer, C.E. (1985). 'Top level management priorities in different stages of the organizational life cycle'. The Academy of Management Journal, 28: 4, 799-820.

Strauss, A. and Corbin J.M. (1990). Basics of Qualitative Research: Grounded Theory Procedures and Techniques, Newby Park, CA: Sage Publications, Inc.

Thietart, R.A. and Vivas, R. (1984). 'An empirical investigation of success strategies for businesses along the product life cycle'. Management Science, 30: 12, 1405-1423.

Ulrich, D. (1998). 'A new mandate for human resources'. Harvard Business Review, 76, 124-134.

Ulrich, D., Younger, J., Brockbank, W. and Ulrich, M.D. (2012). HR from the Outside In: Six Competencies for the Future of Human Resources, New York, NY: McGraw-Hill Education.

Ulrich, D., Younger, J., Brockbank, W. and Ulrich, M. D. (2013). 'The state of the HR profession'. Human Resource Management, 52: 3, 457-471.

Vakola, M. (2014). 'What's in there for me? Individual readiness to change and the perceived impact of organizational change'. Leadership \& Organization Development Journal, 35: $3: 195-209$.

Winstanley, D. and Woodall, J. (2000). 'The ethical dimension of human resource management'. Human Resource Management Journal, 10: 2, 5-20. 
Wright, C. (2008). 'Reinventing human resource management: business partners, internal consultants and the limits to professionalization'. Human Relations, 61: 8, 10631086.

Yin, R. (2009). Case Study Research: Design and Methods, Thousand Oaks, CA: Sage Publications, Inc. 
TABLE 1

Summary of Participants

\begin{tabular}{|c|c|c|c|c|}
\hline Organisation & Insurance Co & Transit Inc & $\begin{array}{c}\text { Energy Ltd } \\
\mathbf{2 0 0 7}\end{array}$ & $\begin{array}{c}\text { Energy Ltd } \\
2012\end{array}$ \\
\hline $\begin{array}{l}\text { Approx. No. of } \\
\text { Employees in } \\
\text { UK }\end{array}$ & 1,900 & 4,000 & 1000 & 1200 \\
\hline Sector & $\begin{array}{c}\text { Private } \\
\text { (Multi-national) }\end{array}$ & Public & Private & Private \\
\hline $\begin{array}{c}\text { Total } \\
\text { Participants }\end{array}$ & 9 & 9 & 18 & $\begin{array}{c}19+\text { Employee } \\
\text { focus group } \\
(n=7)\end{array}$ \\
\hline $\begin{array}{c}\text { Senior } \\
\text { Management }\end{array}$ & $\begin{array}{c}1 \\
\text { (VP Adm.) }\end{array}$ & $\begin{array}{c}1 \\
(\mathrm{CEO})\end{array}$ & $\begin{array}{c}4 \\
\text { (Fin. Dir., GM, } \\
\text { Sp. Ops Dir., } \\
\text { Construction } \\
\text { Dir.) }\end{array}$ & $\begin{array}{c}3 \\
\text { (Asset Man. Dir, } \\
\text { Construction } \\
\text { Dir. Ops Dir.) }\end{array}$ \\
\hline $\begin{array}{c}\text { Line/Functional } \\
\text { Management }\end{array}$ & 3 & 4 & 8 & 9 \\
\hline Senior HR & $\begin{array}{c}2 \\
\text { (HR Dir., } \\
\text { Resourcing Dir.) }\end{array}$ & $\begin{array}{c}1 \\
\text { (HR Dir.) }\end{array}$ & $\begin{array}{c}3 \\
\text { (HR Dir., } 2 \\
\text { Senior HRBPs) }\end{array}$ & $\begin{array}{c}2 \\
\text { (HR Dir., Senior } \\
\text { HRBP) }\end{array}$ \\
\hline $\begin{array}{l}\text { HRBP or HR } \\
\text { Advisor level }\end{array}$ & 3 & 3 & 3 & 5 \\
\hline
\end{tabular}


TABLE 2

Case Study Organisations

\begin{tabular}{|c|c|c|c|}
\hline & Insurance Co & Transit Inc & Energy Ltd \\
\hline $\begin{array}{l}\text { HRBP } \\
\text { Approach }\end{array}$ & Not formalised. & $\begin{array}{c}\text { Operating } \\
\text { successfully. }\end{array}$ & Embedded. \\
\hline HRBP Direction & $\begin{array}{l}\text { Elements exist that } \\
\text { could form the } \\
\text { foundation of a formal } \\
\text { HRBP approach. }\end{array}$ & $\begin{array}{l}\text { Stakeholders have } \\
\text { bought-in to the } \\
\text { concept and see the } \\
\text { benefits. }\end{array}$ & $\begin{array}{l}\text { Beginning to } \\
\text { experience "cosiness" } \\
\text { and overreliance. }\end{array}$ \\
\hline $\begin{array}{l}\text { HR Professional } \\
\text { Role }\end{array}$ & $\begin{array}{l}\text { Resourcing and } \\
\text { traditional, } \\
\text { transactional duties. }\end{array}$ & $\begin{array}{l}\text { Input into business } \\
\text { decisions and } \\
\text { involvement in the } \\
\text { strategic OD initiative. }\end{array}$ & $\begin{array}{l}\text { HRBPs respected by } \\
\text { their LMPs, assertive } \\
\text { in their role, and } \\
\text { understand how to } \\
\text { effectively partner. }\end{array}$ \\
\hline Other Issues & $\begin{array}{l}\text { Employee base is } \\
\text { mostly white-collar } \\
\text { with few employment } \\
\text { relations issues. }\end{array}$ & $\begin{array}{l}\text { Presence of a HR } \\
\text { Service Centre } \\
\text { alleviates some of the } \\
\text { transactional burden. }\end{array}$ & $\begin{array}{l}\text { The phenomenon of } \\
\text { LMPs transferring to } \\
\text { HR roles is emerging. }\end{array}$ \\
\hline
\end{tabular}


TABLE 3

\section{Coding Development}

\begin{tabular}{|c|c|c|}
\hline $\begin{array}{l}\text { Stage I: Open Coding } \\
\text { (Sample Codes) }\end{array}$ & $\begin{array}{l}\text { Stage II: Axil Coding } \\
\text { (Initial Categorisation) }\end{array}$ & $\begin{array}{c}\text { Stage III: } \\
\text { Selective Coding }\end{array}$ \\
\hline $\begin{array}{l}\text { HR Professional } \\
\text { - } \quad \text { HR is strategic } \\
\text { - } \quad \text { Kisibility } \\
\text { - } \quad \text { Delivering on bread and } \\
\text { butter } \\
\text { LMP Partner } \\
\text { - } \quad \text { Buy-In } \\
\text { - } \quad \text { HR expertise needed } \\
\text { - } \quad \text { Relational skills } \\
\text { Relationship } \\
\text { - 'In it together' } \\
\text { - } \quad \text { Partnership working } \\
\text { - } \quad \text { Challenge each other } \\
\text { - } \quad \text { Trust between partners } \\
\text { - } \quad \text { Productive partnerships } \\
\text { - } \quad \text { Talking the same language } \\
\text { - } \quad \text { Finding the right person } \\
\text { - } \quad \text { Maintaining role } \\
\text { - } \text { understanding } \\
\text { Organisation } \\
\text { - Prevailing culture } \\
\text { - Totally embedded }\end{array}$ & $\begin{array}{l}\text { (Re) Establishing the } \\
\text { Relationship } \\
\text { - } \quad \text { HRBP building credibility } \\
\text { - } \quad \text { FLM developing HR } \\
\text { expertise } \\
\text { - } \quad \text { Developing effective } \\
\text { partnerships (handholding) } \\
\text { - } \quad \text { HRBP handing over } \\
\text { - } \quad \text { FLM taking the lead } \\
\text { Devolution } \\
\text { - HRBP conceding } \\
\text { - } \quad \text { FLM regressing } \\
\text { Cosiness Setting In } \\
\text { - HRBP moving on/up } \\
\text { - } \quad \text { FLM refreshing } \\
\text { Integration of HRBP and S/LM } \\
\text { Role } \\
\text { - HRBP outside in } \\
\text { - } \quad \text { FLM relishing HR } \\
\quad \text { responsibility }\end{array}$ & $\begin{array}{l}\text { The final stages } \\
\text { and relationship } \\
\text { dynamics can be } \\
\text { seen in Table } 4\end{array}$ \\
\hline
\end{tabular}


TABLE 4

Elements of the HRBP Lifecycle Model

\begin{tabular}{|c|c|c|c|}
\hline \multicolumn{2}{|c|}{ Stage } & $\begin{array}{l}\text { Relationship } \\
\text { Culture }\end{array}$ & $\begin{array}{c}\text { HRBP Competency } \\
\text { Domains }\end{array}$ \\
\hline \multicolumn{2}{|c|}{ 1. Exploration } & & Strategic Positioner \\
\hline \multicolumn{2}{|c|}{ Assessing the readiness for the HRBP approach. } & Fragmented & $\begin{array}{l}\text { Change Champion } \\
\text { Capability Builder }\end{array}$ \\
\hline \multicolumn{2}{|c|}{$\begin{array}{l}\text { 2. Developing an Effective Partnership } \\
\text { Establishing the HRBP-LMP relationship to enable } \\
\text { strategic HRM and HR devolution to line. }\end{array}$} & Networked & Credible Activist \\
\hline $\begin{array}{l}\text { 3. Maintaining, } \\
\text { Excelling \& }\end{array}$ & Challenge 1: Maintaining & Communal & Capability Builder \\
\hline Maladaptation & Challenge 2: Excelling & Communal & $\begin{array}{l}\text { Change Champion } \\
\text { HR Innovator and }\end{array}$ \\
\hline $\begin{array}{l}\text { Unfolding dynamics } \\
\text { causing three } \\
\text { potential challenges. }\end{array}$ & Challenge 3: Maladaptation & Networked & Integrator \\
\hline
\end{tabular}


FIGURE 1

HRBP Lifecycle Model

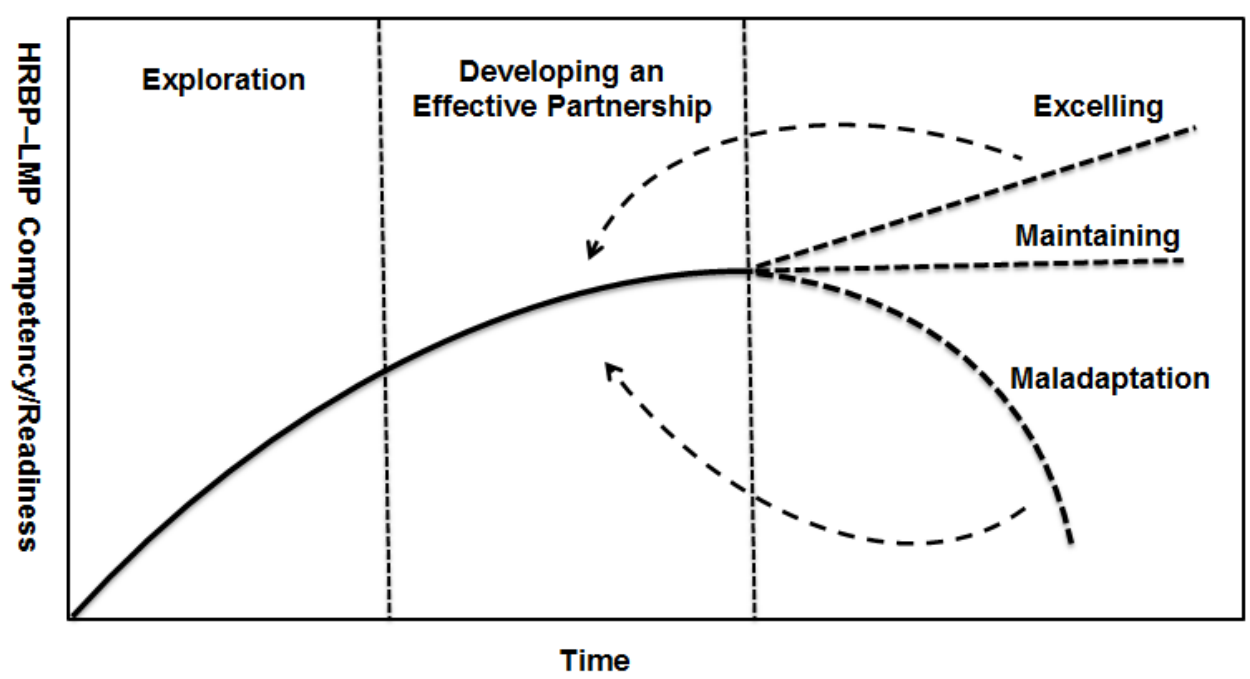

